\title{
Study on the Water Surge Height Line of Landslide Surge of Linear River course Reservoir Based on FLOW-3D
}

\author{
Wen Chen, Peng Hui, Jin Ke, Wu Fan and Yin Shaofei \\ College of Hydraulic \& Environmental Engineering, China Three Gorges University, Yichang 443002, China
}

\begin{abstract}
The occurrence and transmission attenuation of surge is always a problem that researchers pay much attention to. The influence of the first wave height of landslide surge and the following transmission attenuation of surge are involved with many factors, which are mainly: landslide water entry angle, river course depth, river course geometrical properties and landslide mass and material, etc.. This thesis is mainly a research on the properties and transmission attenuation rules of landslide surge which is caused by linear narrow river course. Numerical value simulation will be applied in this thesis to discuss about the features and rules of the occurrence and transmission of surge in different landslide water entry angles and under different influences.
\end{abstract}

Key words: Landslide, numerical simulation, first wave, spread, FLOW-3d.

\section{Introduction}

In hydraulic engineering, landslide occurs frequently. The surge sparked by landslides has the potential to cause large geological disasters to water conservancy facilities, port and waterway engineering, and life and property of nearby people. Such as Italy Vaiontlandslide [1] and Tangyanguang landside of Zhexireservoir [2]. At present, more and more high dam built in the valley. The landslide surge problem which appears to be more prominent. To correctly predict possible reservoir landslide is an important content of feasibility in engineering.

At present, landslide surge research mainly exist complex movement mechanism of landslide, the interaction mechanism between fluid and landslide mass, and the interaction mechanism between fluid and the reservoir bank is not clear and so on. This kind of research is carried out based on some basic assumptions. In model test, the landslide mass is assumed to be a rigid sliding block which is submerged or partially

Corresponding author: Peng Hui, professor, main research field: hydraulic engineering. submerged by water body [3]. Fritz, H. M., Moster, P. [4] use pneumatic device to simulate the more regular granular landslide flow. In the aspect of numerical simulation, most models are developed on the basis of the following two basic assumptions: One is the surge is generated by the specified boundary and the fluid movement, this assumption is difficult to account for the interaction between the landslide body and the fluid; The other one is the governing equations of water body in the vicinity of the impact area of the landslide are simplified as the shallowwater equations $[5,6]$. When the impact velocity of the sliding block is larger, the calculation precision of the basin will be reduced. Heinrich, P. [7] set up a three-dimensional numerical model, solving the problem of two-phase mixture flow (solid phase and liquid phase) by solving the Euler equations, and overcome the problems mentioned above two assumptions. Subsequently, an improved non-gridded Moving Particle Semi-implicit method is used to simulate the landslide surge. In this method, the Lagrange method is used to avoid the dissipation problem in numerical calculation [8]. In the aspect of free surface tracking, the numerical calculation method 
mainly includes Level-set method, MAC method, VOF method and light sliding particle method $[9,10]$.

In this paper, by using FLOW-3d three-dimensional fluid computing software, the simulation model is based on the actual physical experiment model, and turbulence model uses RNGk- $\varepsilon$ model, and free surface tracking uses VOF method.

\section{Numerical Calculation Model}

This paper based on the physical model experiment, according to the basic principle of finite element method, simulation study on landslide surge numerical values under variable angle and changing water depth of linear river course.

The model is divided into three parts, the sliding block, the sliding plate and the water tank. The size of the rectangular sliding block is $0.4 \mathrm{~m} * 0.2 \mathrm{~m} * 0.15 \mathrm{~m}$; the density of material is $2,200 \mathrm{~kg} / \mathrm{m}^{3}$; the size of the sliding block is $1.5 \mathrm{~m} * 0.3 \mathrm{~m}$; The water tank is formed by the connection of the straight line type rectangular channel section of $2.5 \mathrm{~m} * 0.5 * 1.0 \mathrm{~m}$ and the rectangular reservoir of $1.5 \mathrm{~m} * 1.0 \mathrm{~m} * 1.0 \mathrm{~m}$. As shown in Figs. 1, 2.

The numerical model is 1:1 from physical model, as shown in Fig. 3.

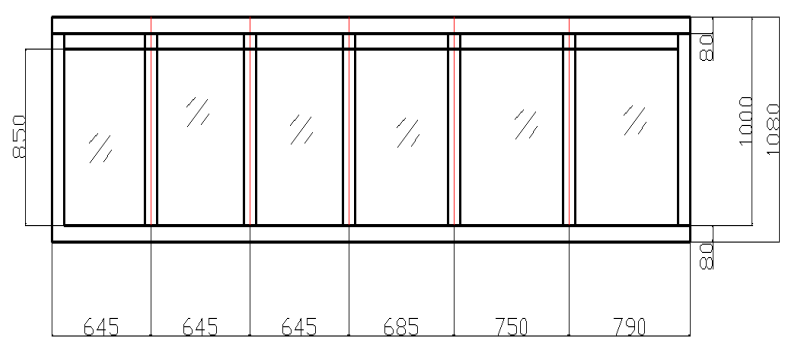

Fig. 1 Elevation view of the model Unit mm.

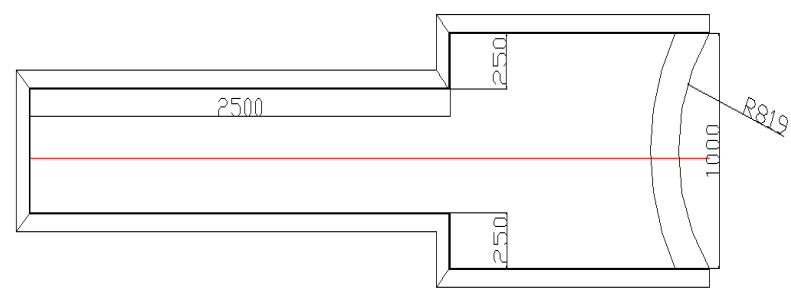

Fig. 2 Overhead view of the model Unit $\mathbf{m m}$.

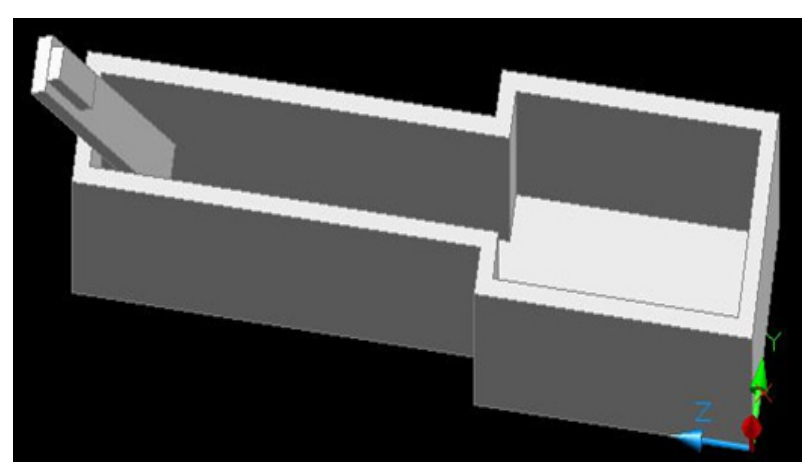

Fig. 3 Geometric numerical model.

Create a finite element model, using a meshblock to build the sink grid region, grid size is 0.015 , total grid number is $3,733,200$ overall grid quality is good. The surrounding and the bottom of the meshblock are no slip boundary, and the top is the free surface boundary. (boundary condition in Fig. 4, and grid partition graph in Fig. 5).

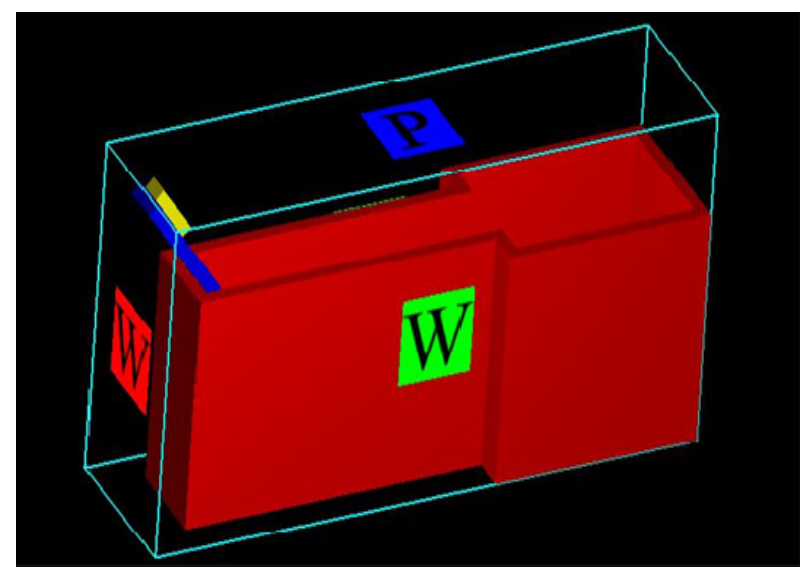

Fig. 4 Boundary condition.

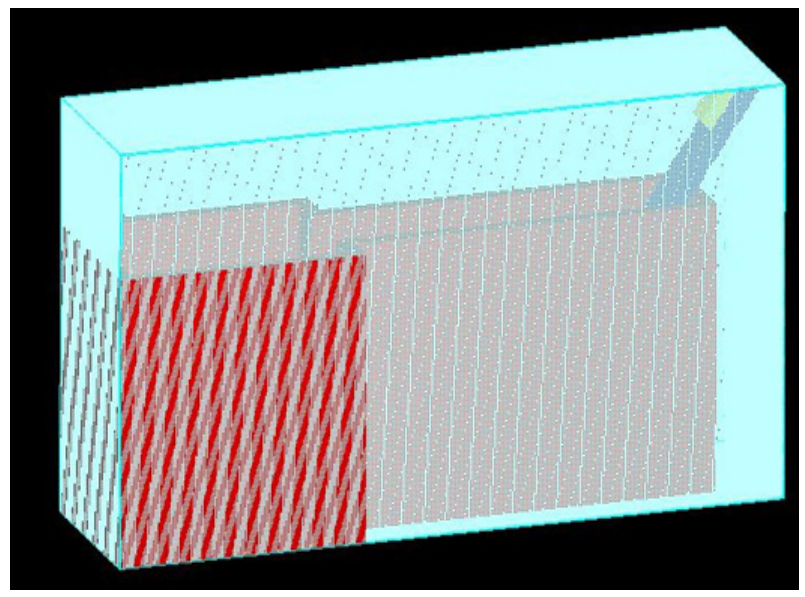

Fig. 5 Grid partition graph. 
In this numerical study, think that the block in the process of decline for the rigid body movement, deformation and any damage does not occur, the fluid is set to Newtonian fluid, Turbulence model using model RNGk- $\varepsilon$, the sliding block is only in gravity (setting the gravity acceleration to $9.81 \mathrm{~m} / \mathrm{s}^{2}$ ), and the sliding plate is sliding into the water from the top of the slide plate. Without considering the air resistance, the initial sliding angle is 50 degrees, the initial water depth is $0.5 \mathrm{~m}$, the time step is $0.0625 \mathrm{~s}$, and the calculation time is $5 \mathrm{~s}$.

\section{Study on the Water Surge Height Line of Landslide Surge of Linear River course Reservoir}

\subsection{Simulation Study on Landslide Surge Numerical} Values under Variable Angle and unchanging Water Depth of Linear River course

The only variable is the angle, other parameters are unchanged. So the sliding friction coefficient is $\mu=0$ in the initial condition. The slide from the same height (from the height of the water surface is $\mathrm{H}=1.0 \mathrm{~m}$ ), fixed water depth is $\mathrm{h}=0.5 \mathrm{~m}$, all the parameters are calculated at the same time except for the angle, conditions including the landslide angle of $40^{\circ}, 50^{\circ}$, $60^{\circ}, 70^{\circ}$ and $80^{\circ}$ degrees of the landslide simulation. The whole model is divided into three sections and 13 monitoring stations, straight channel section (width $\mathrm{d} 1$ $=0.5 \mathrm{~m}$ ), reservoir section (width $\mathrm{d} 2=1.0 \mathrm{~m}$ ) and abrupt change (from d1 to d2), 5 measuring points are arranged in the straight channel section as follows: $\mathrm{x}=$ $1.5 \mathrm{~m}, \mathrm{x}=1.7 \mathrm{~m}, \mathrm{x}=1.9 \mathrm{~m}, \mathrm{x}=2.1 \mathrm{~m}, \mathrm{x}=2.3 \mathrm{~m} ; 5$ monitoring points are also arranged in the mutation broadening section as follows: $\mathrm{x}=2.3 \mathrm{~m}, \mathrm{x}=2.4 \mathrm{~m}, \mathrm{x}$ $=2.4 \mathrm{~m}, \mathrm{x}=2.6 \mathrm{~m}, \mathrm{x}=2.7 \mathrm{~m}$, reservoir section also arranged 5 monitoring points as follows: $\mathrm{x}=2.7 \mathrm{~m}, \mathrm{x}=$ $3.0 \mathrm{~m}, \mathrm{x}=3.3 \mathrm{~m}, \mathrm{x}=3.6 \mathrm{~m}, \mathrm{x}=4.0 \mathrm{~m}$.

According to the above conditions for numerical calculation, 5 operating conditions are primary waves propagation along the height of the Table 1.
Table 1 Five conditions of the first wave of high initial value.

\begin{tabular}{lllllll}
\hline $\begin{array}{c}\text { Location and } \\
\text { angle }\end{array}$ & $40^{\circ}$ & $50^{\circ}$ & $60^{\circ}$ & $70^{\circ}$ & $80^{\circ}$ \\
\hline $\mathrm{k} 1$ & 1.5 & 43 & 45 & 49 & 40 & 31 \\
$\mathrm{k} 2$ & 1.7 & 40 & 43 & 46 & 38 & 30 \\
$\mathrm{k} 3$ & 1.9 & 43 & 47 & 50 & 40 & 31 \\
$\mathrm{k} 4$ & 2.1 & 37 & 40 & 43 & 35 & 29 \\
$\mathrm{k} 5$ & 2.3 & 27 & 33 & 38 & 25 & 21 \\
$\mathrm{k} 6$ & 2.4 & 25 & 30 & 35 & 23 & 20 \\
$\mathrm{k} 7$ & 2.5 & 19 & 21 & 27 & 18 & 14 \\
$\mathrm{k} 8$ & 2.6 & 16 & 18 & 21 & 16 & 11 \\
$\mathrm{k} 9$ & 2.7 & 13 & 16 & 20 & 14 & 10 \\
$\mathrm{k} 10$ & 3 & 9 & 11 & 12 & 9 & 7 \\
$\mathrm{k} 11$ & 3.3 & 4 & 6 & 7 & 6 & 3 \\
$\mathrm{k} 12$ & 3.6 & 2 & 5 & 6 & 6 & 3 \\
$\mathrm{k} 13$ & 4 & 7 & 11 & 14 & 12 & 8 \\
\hline
\end{tabular}

To observe the 5 conditions of the first wave of high initial value, when the landslide angle into the water is small, with the increase of the angle, the maximum wave height increases gradually, but the angle exceeds a certain value, with the increase of the angle, the maximum surge high decreased. This study found that when the slope angle is 60 degrees, the first wave caused maximum height.

According to analysis, ordinary wave or huge surge caused by landslide both follow the wave-particle dualism in the physics. The wave-particle dualism of surge transmission is mainly reflected after the slider impacts the water and form surge. On one hand, water reflects that particle property and shocks upside down; on the other hand, water reflects wave property and spreads in all directions. Surge height is determined by the above two parts. Therefore, considering the influence of slider's component velocity in different coordinate directions: slider's component velocity $\mathrm{Vx}$ (downside along the river course in $\mathrm{z}$ direction), slider's component velocity $\mathrm{Vy}$ (being vertical to the river course direction, y direction is ignored), $\mathrm{Vz}$ (upside, being vertical to the water in $\mathrm{z}$ direction), the authors can see that the bigger the angle is, the smaller $\mathrm{Vx}$ is and the larger the $\mathrm{Vz}$ is. $\mathrm{Vx}$ and $\mathrm{Vz}$ can both influence the surge height. The authors learn from simulated computation value that $\mathrm{Vx}$ 's influence to 
the surge height is mainly reflected on the undulatory property, while Vz's influence to surge height is mainly reflected on particle property. $\mathrm{Vx}$ and $\mathrm{Vz}$ overlap and combine with each other which leads to the terminal surge height change. Namely surge height maximum appears when the landslide angle is $60^{\circ}$. However, as the working condition changes in $10^{\circ}$, the most dangerous angle of the landslide surge is about $60^{\circ}$.

\subsection{Simulation Study on Landslide Surge Numerical} Values under Fixed Angle and Changing Water Depth of Linear River course

The only variable is the angle, other parameters are unchanged, in order to ensure the water entry time slider speed is the same, $\mathrm{H}=1.0 \mathrm{~m}$ from the same height every time, block size is still the same as $0.4 \mathrm{~m}$ * $0.2 \mathrm{~m} * 0.15 \mathrm{~m}$, the entry point location remains the same, the angle of sliding plate is fixed to $60^{\circ}$, the initial water depth of the 5 conditions are $\mathrm{h}=0.5 \mathrm{~m}, \mathrm{~h}$ $=0.6 \mathrm{~m}, \mathrm{~h}=0.7 \mathrm{~m}, \mathrm{~h}=0.8 \mathrm{~m}, \mathrm{~h}=0.9 \mathrm{~m}$. The whole model is divided into three sections and 13 monitoring stations, straight channel section (width $\mathrm{d} 1=0.5 \mathrm{~m}$ ), reservoir section (width $\mathrm{d} 2=1.0 \mathrm{~m}$ ) and abrupt change (from $\mathrm{d} 1$ to $\mathrm{d} 2$ ), 5 measuring points are arranged in the straight channel section as follows: $\mathrm{x}=1.5 \mathrm{~m}, \mathrm{x}=1.7$ $\mathrm{m}, \mathrm{x}=1.9 \mathrm{~m}, \mathrm{x}=2.1 \mathrm{~m}, \mathrm{x}=2.3 \mathrm{~m} ; 5$ monitoring points are also arranged in the mutation broadening section as follows: $\mathrm{x}=2.3 \mathrm{~m}, \mathrm{x}=2.4 \mathrm{~m}, \mathrm{x}=2.4 \mathrm{~m}, \mathrm{x}=$ $2.6 \mathrm{~m}, \mathrm{x}=2.7 \mathrm{~m}$, reservoir section also arranged 5 monitoring points as follows: $\mathrm{x}=2.7 \mathrm{~m}, \mathrm{x}=3.0 \mathrm{~m}, \mathrm{x}=$ $3.3 \mathrm{~m}, \mathrm{x}=3.6 \mathrm{~m}, \mathrm{x}=4.0 \mathrm{~m}$ as well.

According to the above conditions for numerical calculation, 5 operating conditions are primary waves propagation along the height of the Table 3.

The authors can get the following conclusion according to the surge transmission water surge height diagram under 5 different working conditions:

The authors firstly observe the first wave height at $1.5 \mathrm{~m}$ under 5 working conditions, namely the first wave height of surge. It can be seen evidently that with
Table $2 \mathrm{X}, \mathrm{Z}$ direction velocity component under different angles.

\begin{tabular}{llllll}
\hline Angle & $40^{\circ}$ & $50^{\circ}$ & $60^{\circ}$ & $70^{\circ}$ & $80^{\circ}$ \\
\hline $\mathrm{Vx}(\mathrm{m} / \mathrm{s})$ & 3.39 & 2.85 & 2.22 & 1.82 & 0.77 \\
$\mathrm{Vz}(\mathrm{m} / \mathrm{s})$ & -2.85 & -3.39 & -3.84 & -4.16 & -4.36 \\
\hline
\end{tabular}

Table 3 Five conditions of the first wave of high initial value.

\begin{tabular}{lllllll}
\multicolumn{2}{c}{$\begin{array}{c}\text { Location and } \\
\text { water depth }\end{array}$} & $0.5 \mathrm{~m}$ & $0.6 \mathrm{~m}$ & $0.7 \mathrm{~m}$ & $0.8 \mathrm{~m}$ & $0.9 \mathrm{~m}$ \\
\hline $\mathrm{k} 1$ & 1.5 & 49 & 43 & 37 & 35 & 33 \\
$\mathrm{k} 2$ & 1.7 & 46 & 42 & 37 & 36 & 32 \\
$\mathrm{k} 3$ & 1.9 & 50 & 42 & 35 & 35 & 33 \\
$\mathrm{k} 4$ & 2.1 & 43 & 40 & 37 & 31 & 33 \\
$\mathrm{k} 5$ & 2.3 & 38 & 37 & 26 & 25 & 38 \\
$\mathrm{k} 6$ & 2.4 & 35 & 29 & 21 & 21 & 24 \\
$\mathrm{k} 7$ & 2.5 & 27 & 24 & 18 & 18 & 20 \\
$\mathrm{k} 8$ & 2.6 & 21 & 20 & 15 & 13 & 15 \\
$\mathrm{k} 9$ & 2.7 & 20 & 16 & 12 & 10 & 11 \\
$\mathrm{k} 10$ & 3 & 12 & 11 & 7 & 4 & 4 \\
$\mathrm{k} 11$ & 3.3 & 7 & 6 & 2 & 0 & 0 \\
$\mathrm{k} 12$ & 3.6 & 6 & 5 & 4 & & \\
$\mathrm{k} 13$ & 4 & 14 & 11 & 8 & & \\
\hline
\end{tabular}

the water depth increases from $0.5 \mathrm{~m}$ to $0.9 \mathrm{~m}$, the first wave heath lowers from $49 \mathrm{~mm}$ to $33 \mathrm{~mm}$, which means that the first wave height decreases with the increasing water depth when other conditions remain unchanged. According to analysis, in the initial condition, when the same slider slides down from the same position and in the same angle, it gains the same sliding velocity when entering into the water, namely the equal energy. Then, the slider's energy will be transferred to the water, the deeper the water is, the more water media are and more consumption of energy in the slider's movement in water. Therefore, the smaller the initial energy of water is, the lower the initial wave height is. Additionally, it can be seen that with the increasing depth of the water, the initial surge height doesn't decrease in linearpattern. Instead, with the increasing water depth, the decreasing initial surge height declines. According to analysis, the initial surge height is directly related to energy transmitted from the slider to the water when it enters the water. The deeper the water is, the more media is included in the water and more energy is consumed, which definitely leads to 
less energy being transmitted. But the decrease is limited. The slider will finally be fully soaked in the water. After the initial surge height comes to an end, the slider suffers from gravity and water pressure in water and gradually sank to the bottom of the water, when it's not related to the surge. Therefore the initial surge height is influenced during the period when the slider exchanges energy with water until the slider is fully surrounded by the water. The initial surge height will gradually decrease with the increasing depth of water. The influence will gradually decline, instead of changing in lineage.

Through the comparison of K5-K8 trend lines under five working conditions, the authors find the same sharp decrease. As this section changes from $2.3 \mathrm{~m}$ of river course to $2.6 \mathrm{~m}$ of reservoir section, from narrow to broad. When the surge reaches here, water media expands and the attenuation and enlargement of surge height transmission is normal.

Among the five working conditions, when the water depth is $0.8 \mathrm{~m}$ and $0.9 \mathrm{~m}$, the surge height turns 0 when it comes to the monitoring point $\mathrm{K} 11$, which means that the surge disappears when it reaches here. Additionally, the authors can observe that under 5 working conditions the gradient of surge transmission trend line is basically horizontal in different water depths, which doesn't influence the attenuation degree of surge transmission. As according to analysis, authors have already learned that the surge formed when the slider slide into the water is shallow wave under the water depth of $0.5 \mathrm{~m}$, they are also shallow waves when the water depth changes from $0.6 \mathrm{~m}$ to $0.9 \mathrm{~m}$ which could only influence water media within a limited area. Surge transmits in the surface of the water. Actually, under different water depths, the transmission of surge is not heavily influenced. Therefore during transmission, the gradients of transmission attenuation curve under five working conditions are the same; meanwhile, the deeper the water is, the lower the initial surge height is. Therefore, the surge transmits to a certain distance in the water depth of $0.8 \mathrm{~m}$ and $0.9 \mathrm{~m}$ when its energy is fully consumed and the surge height turns to zero.

\section{Main Conclusions}

In the process of discovery and propagation law of wave height is conventional along the increase of propagation distance becomes inconsistent, a maximum value occurs in them, the position of the maximum value is $1.9 \mathrm{~m}$ when the water depth of the $0.5 \mathrm{~m}$ water depth is at 60 degrees. This distance is related to the channel size, characteristics, initial water depth and so on.

The same depth and different angle conditions, landslide initial surge in the first wave, neither angle gets larger surge height increased with nor with angle gets larger surge height reduction, but when the slope angle of about 60 degrees, the first wave surge height value reached the maximum; and for the same slip angle in different water depth, with the larger initial water depth, initial surge high low, initial surge high is not reduced linearly, but with the increase of water depth, initial surge high decreases slowly.

Surge height value is high with the propagation distance attenuation is greater, but the overall attenuation of the same magnitude, then that is linear channel spread surge, surge height value greater attenuation is larger, but the attenuation of the same magnitude. The internal energy of water becomes smaller with the increase of propagation distance. Mutations in the emergence of widening surge height drop faster

The linear attenuation river surge decay faster than reservoir, linear channel segment width is $\mathrm{d} 1=0.5 \mathrm{~m}$, Reservoir segment width is $\mathrm{d} 2=1.0 \mathrm{~m}$. The greater the width of the river, the greater the wave theory should be, because the greater the width of the water surface medium, therefore more explanation, the wave propagation distance away will slow decay.

\section{References}

[1] Kiersch, G. A. 1964. "Vajont Reservoir Disaster." Civil Engineering (ASCE) 34 (3): 32-39.

[2] Hunan Hydro \& Power Design Institute. 1983. Slope 
course Reservoir Based on FLOW-3D

Engineering Geology. Beijing: Water Conservancy and Electric Power press.

[3] Wiegel, R. L. 1995. "Laboratory Studies of Gravity Waves Generated by the Movement of A Submerged Body." Transactions-American Geophysical Union 36 (5): 759-774.

[4] Fritz, H. M., Moster, P. 2003. "Pneumatic Landslide Generator." International Journal of Fluid Power 173 (2): 223-233.

[5] Sander, J., Hutter, K. 1992. "Evolution of Weakly Non-linear Channelized Shallow Water Waves Generated by A Moving Boundary."Acta Mechanic 91: 119-155.

[6] Sander, J., Hutter, K. 1996. "Multiple Pulsed Debris Avalanche Emplacement at Mount St. Helens in 1980: Evidence form Numerical Continuum Flow Simulation.”
Acta Mechanic 115:133-149.

[7] Heinrich, Ph. 1992. "Nonlinear Water Waves Generated by Submarine and Aerial Landslides." Journal of Waterway, Port, Coast, and Ocean Engineering, ASCE 118: 249-266.

[8] Ataie-Ashtiani, B., Farhadi, L. A. 2006. "Stable Moving-particle Semi-implicit Method for Free Surface Flow." Fluid Dynamic Research 38 (4): 241-256.

[9] Monaghan, J. J. 1994. "Simulating Free Surface Flows with SPH." Journal of Computational Physics 110: 399-406.

[10] Ataie-Ashtiani, B., Shobeyri, G. 2001. "Numerical Simulation of Landslide Impulsive Waves by Incompressible Smoothed Particle Hydrodynamic." International Journal for Numerical Method in Fluids 56: 209-232. 